\title{
Note
}

\section{Purification of papain by affinity chromatography}

\author{
WAN-JR SYU, SHIH-HSIUNG WU and KUNG-TSUNG WANG* \\ Graduate Institute of Biochemical Sciences, National Taiwan University, and Institute of Biological Chem- \\ istry*, Academia Sinica, P.O. Box 23-106, Taipei (Taiwan)
}

(Received February 8th, 1983)

Many proteins such as enzymes, antibodies and lectin have been successfully purified by affinity chromatography using specific binding ligands ${ }^{1-3}$. Proteolytic enzymes usually have peptidase, esterase and amidase activities and sometimes are used for the resolution of D,L-amino acids by specific hydrolysis of the L-enantiomers of amino acid derivatives, despite the presence of the D-enantiomers ${ }^{4,5}$. A number of synthetic peptides and their analogues are used for studying enzyme activities. Among them, those containing D-amino acids are usually found to be inhibitors or poor substrates for the enzymes. These compounds seem to be suitable for the ligands of affinity adsorbents and several successful examples have been reported; e.g. Dtryptophan methyl ester for $\alpha$-chymotrypsin ${ }^{1}$ and bromelain ${ }^{6}, \mathrm{D}$-arginine, D-phenylalanine and D-tryptophan for carboxypeptidase $\mathrm{B}^{7}$ and L-phenylalanine-D-phenylalanine methyl ester for pepsin ${ }^{8}$.

The isolation and purification of papain from commercially available latex (Carica papaya) is carried out by precipitating a fraction from solutions of the latex by the ammonium sulphate fractionation method of Kimmel and Smith ${ }^{9}$. However it is difficult to obtain pure papain by this method, the product usually being contaminated by chymopapain, unless the protein concentration is carefully controlled. Affinity chromatography was first introduced by Blumbery et al. ${ }^{10}$ for the purpose of purifying papain. These workers used Gly-Gl-Tyr(Bzl)-Arg as a ligand that the specific activity of the purified papain increased to only twice the value of the original preparation. In this communication, we report the use of three kinds of affinity column for the purification of papain; ten-fold purification was obtained.

\section{MATERIALS AND METHODS}

Sepharose 4B was obtained from Pharmacia (Sweden). N,N, $N^{\prime}, N^{\prime}-$ Tetramethylethyldiamine (TEMED), acrylamide, N, $\mathrm{N}^{\prime}$-methylenediacrylamide, Amido black 10B, $\varepsilon$-aminocaproic acid ( $\varepsilon$-Acp) and guanidine hydrochloride were purchased from E. Merck (G.F.R.). Cyanogen bromide, 2-mercaptoethanol and N-2benzoyl-L-arginine- $p$-nitroanilide hydrochloride (BAPNA) were obtained from Sigma (U.S.A.), dicyclohexylcarbodiimide (DCCI) from Pierce (U.S.A.), carbobenzoxyl chloride (Z-Cl) and D-phenylalanine (D-Phe) from Protein Research Foundation (Japan), L-leucine (L-Leu) from Kyowa Fermentation Co. (Japan) and ethylene- 
diaminetetraacetic acid (EDTA) from Koch-Light (Great Britain). Papain was purchased from Tree Co. (Taiwan).

\section{Preparation of amino acid derivatives}

Carbobenzoxyl-\&-aminocaproic acid dicyclohexylammonium salt, D-phenylalanine methyl ester hydrochloride, D-phenylalaninc cthyl ester hydrochloride and Lleucine methyl ester hydrochloride were prepared according to established methods $^{11}$.

\section{Synthesis of peptides}

The three peptides, $\varepsilon$-aminocaproyl-D-phenylalanine methyl ester $(\varepsilon$-Acp-DPhe-OCH$H_{3}$, $\varepsilon$-aminocaproyl-D-phenylalanine ethyl ester $\left(\varepsilon\right.$-Acp-D-Phe- $\left.\mathrm{C}_{2} \mathrm{H}_{5}\right)$ and $\varepsilon$ aminocaproyl-L-leucyl-D-phenylalanine ( $\varepsilon$-Acp-L-Leu-D-Phe), were synthesized by conventional coupling and deprotecting methods ${ }^{11}$.

\section{Immobilization of the three ligands on agarose gel}

Thoroughly washed, decanted agarose $(50 \mathrm{ml})$ was suspended in an equal volume of water. Finely divided cyanogen bromide $(10 \mathrm{~g})$ was added in one portion to the stirred suspension. The $\mathrm{pH}$ of the solution was adjusted and maintained at $\mathrm{pH} 11$ with $5 \mathrm{M}$ sodium hydroxide solution and the temperature was maintained at $\mathrm{ca} .22^{\circ} \mathrm{C}$ by adding pieces of ice. The reaction was allowed to proceed for ca. 10 min until no more base was required. The activated Sepharose was washed rapidly with 15 volumes of cold water on a Buchner funnel. The wet Sepharose was then added quickly to a solution of the synthetic peptide ligands and the mixture was stirred gently for 24 $\mathrm{h}$ at $4^{\circ} \mathrm{C}$. The peptide ligand-Sepharose conjugate was filtered off and washed thoroughly with $0.1 M$ aqueous sodium hydrogen carbonate and water. The amount of ligands covalently bound to the Sepharose was determined by hydrolysis of the conjugate in $6 \mathrm{M}$ hydrochloric acid for $24 \mathrm{~h}$ at $110^{\circ} \mathrm{C}$ and the quantity of leucine or phenylalanine was estimated on a Yanagimoto Model LC5A amino acid analyser.

\section{Purification of papain}

With the aid of gentle stirring, $10 \mathrm{~g}$ of crude papain was dissolved in $50 \mathrm{ml}$ of $0.02 M$ citrate buffer ( $\mathrm{pH} 6.2$ ) containing $0.001 M$ EDTA. The undissolved material was removed by centrifugation. In order to obtain a clear solution, the supernatant was passed through a filter paper and cooled to $4^{\circ} \mathrm{C}$. All the columns investigated were equilibrated with $0.02 M$ citrate buffer $(\mathrm{pH} \mathrm{6.2)} \mathrm{containing} 0.001 M$ EDTA at $4{ }^{\circ} \mathrm{C}$. The buffer was prepared using boiled, distilled water and the elutions were performed without dripping to eliminate disturbance of oxygen. An excess amount of papain was applied to the columns and washed with buffers, as described in the figure legends.

The eluate was fractionated with monitoring by UV at $280 \mathrm{~nm}$. Owing to the presence of EDTA in the elution buffer (to avoid the Folin-Lowry effect), the concentrations of papain in the fractions were estimated from their absorbances at 280 $\mathrm{nm},\left(E_{1 \%}^{1 \%}=25\right)^{12}$. After reactivation by $\beta$-mercaptoethanol and EDTA solution, the amidase activity of the papain was measured with BAPNA as a substrate according to the method of $\operatorname{Arnon}^{13}$, and the purities of the eluted proteins were examined by disc electrophoresis ${ }^{14}$. 


\section{TABLE I}

THE AMOUNT OF LIGANDS COUPLED TO THE CYANOGEN BROMIDE-ACTIVATED AGAROSE

\begin{tabular}{|c|c|c|c|}
\hline Affinity adsorbent & $\begin{array}{l}\text { Amount of ligand } \\
\text { used for coupling } \\
\text { (mmole/ml of gel) }\end{array}$ & $\begin{array}{l}\text { Amount of ligand } \\
\text { immobilized } \\
\text { (Amole (ml of gel) }\end{array}$ & $\begin{array}{l}\text { Coupling } \\
\text { ratio }(\%)\end{array}$ \\
\hline Sepharose-s-Acp-D-Phe- & 0.13 & $5.8 *$ & 4.5 \\
\hline Sepharose- $\varepsilon$-Acp-D-Phe- $\mathrm{OC}_{2} \mathrm{H}_{5}$ & 0.16 & $6.5 *$ & 4.1 \\
\hline Sepharose $\varepsilon$-Acp-L-Leu-D-Phe-OH & 0.05 & $3.2^{\star \star}$ & 6.4 \\
\hline
\end{tabular}

* Calculated from the phenylalanine content.

* Calculated from leucine or phenylalanine.

\section{RESULTS AND DISCUSSION}

The amounts of the different peptide ligands coupled to the agarose were examined by amino acid analysis, as listed in Table I. Although the ligand $\varepsilon$-Acp-LLeu-D-Phe had a larger structure, its degree of coupling to agarose was higher than the other two ligands. All the investigated columns were washed with $6 \mathrm{M}$ guanidine hydrochloride and then distilled water and then equilibrated with $0.02 M$ citrate buffer ( $\mathrm{pH}$ 6.2) containing $0.001 M$ EDTA. An excess of activated crude enzyme solution was applied to the columns and the elution procedure involved two or three steps depending on the character of columns (see Figs. 1-3). When the eluent contained mercuric ion, it was possible for mercuripapain to be formed and hence it was reactivated by the addition of buffer solution containing $\beta$-mercaptoethanol and EDTA before the amidase activity was measured.

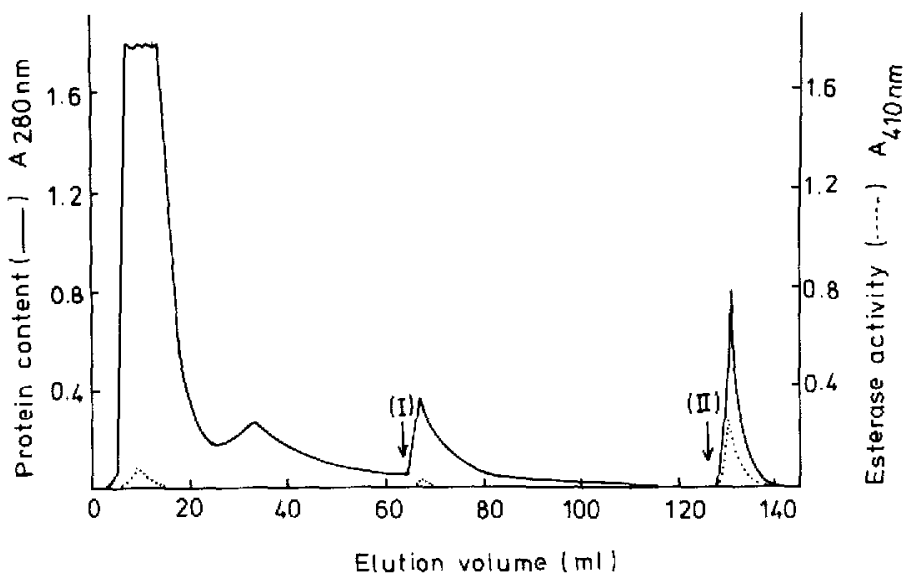

Fig. 1. Chromatography of activated crude papain on the Sepharose- - -Acp-L-Leu-D-Phe-OH column. The column $(9.5 \times 1 \mathrm{~cm})$ was equilibrated with $0.02 M$ citrate, $(\mathrm{pH}$ 6.2) containing $0.001 M$ EDTA. 3-ml volume containing $c a .20 \mathrm{mg}$ of crude papain was applied and $1.5 \mathrm{ml}$ of each fraction was collected. The flow-rate was $20 \mathrm{ml} / \mathrm{h}$. The activity was expressed as the absorbance at $410 \mathrm{~nm}$ after $0.4 \mathrm{ml}$ of eluted solution had been used for amidase assay. The arrows indicate the use of the following eluents: (I) the equilibrium buffer containing $0.3 \mathrm{M}$ sodium chloride; (II) $0.5 \mathrm{n} M$ mercuric chloride; —- protein content, $A_{280} ; \cdots$, enzyme activity. $A_{410}$. 


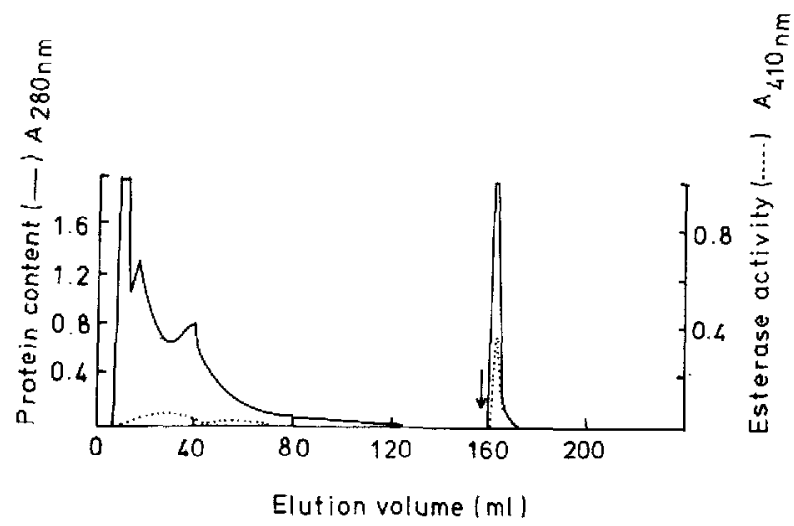

Fig. 2. Chromatography of activated crude papain on the Sepharose- $\varepsilon-A c p-D-P h e-O C_{2} H_{5}$ column. The column $(9.5 \times 1 \mathrm{~cm})$ was equilibrated with $0.02 M$ citrate $(\mathrm{pH} 6.2)$ containing $0.001 M$ EDTA and $0.2 M$ sodium chloride. A 26-mg portion of crude papain dissolved in $4 \mathrm{ml}$ of buffer was applied on to the column which was then eluted with equilibrated buffer. Other conditions were the same as described in Fig. 1. The arrow indicates the point at which the elution buffer containing $0.5 \mathrm{mM}$ mercury(II) chloride was applied; - - protein content, $A_{280}, \cdots \cdots$, enzyme activity, $A_{410}$.

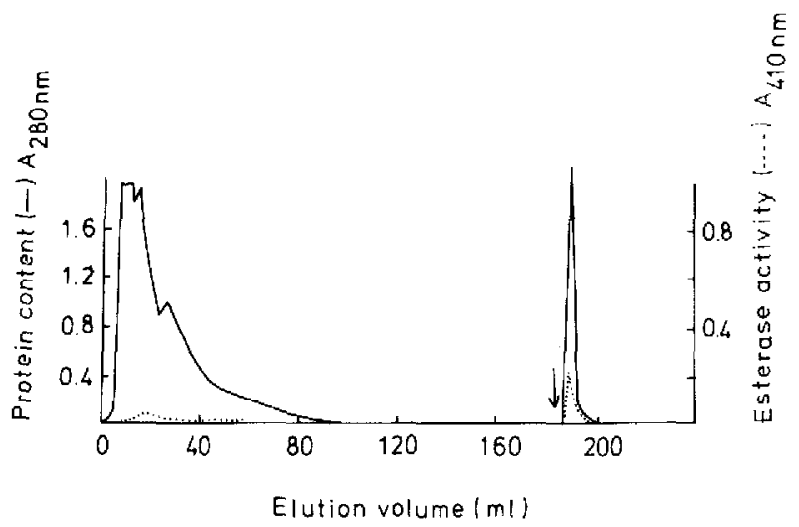

Fig. 3. Chromatography of activated crude papain on the Sepharose-e-Acp-D-Phe-OCH${ }_{3}$ column. Conditions were the same as those in Fig. $2 ;-$, protein content, $A_{280}, \cdots$, enzyme activity, $A_{410}$.

TABLE II

PAPAIN PURIFIED BY THREE KINDS OF BIOSPECIFIC AFFINITY COLUMN

\begin{tabular}{|c|c|c|c|c|}
\hline Gel* & $\begin{array}{l}\text { Initial protein } \\
\text { specific activity } \\
\text { (unitsimg) }\end{array}$ & $\begin{array}{l}\text { Retarded protein } \\
\text { specific activity } \\
\text { (units/mg) }\end{array}$ & $\begin{array}{l}\text { Purification } \\
\text { (folds) }\end{array}$ & $\begin{array}{l}\text { Capacity } \\
\text { units } \\
\text { (mg) }\end{array}$ \\
\hline Sepharose- $\varepsilon$-Acp-D-Phe-OCH 3 & 2.1 & 6.1 & 2.9 & $14.6(2.4 \mathrm{mg})$ \\
\hline Sepharose-s-Acp-D-Phe-OC ${ }_{2} \mathrm{H}_{5}$ & 2.1 & 6.5 & 3.2 & $25.4(3.9 \mathrm{mg})$ \\
\hline Sepharose- $\varepsilon$-Acp-L-Leu-D-Phe-OH $\star \star \star$ & 2.1 & 21.3 & 10.0 & $27.7(1.3 \mathrm{mg})$ \\
\hline
\end{tabular}

* All gels were packed in $9.5 \times 1 \mathrm{~cm}$ columns.

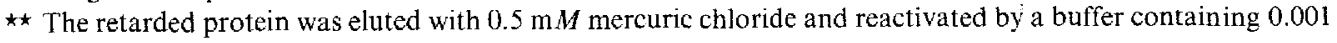
$M$ mercaptoethanol and $0.001 M$ EDTA. 
From the data listed in Table II, the three ligands can all be seen to retard papain, each one having its own efficiency and capacity. The ligands D-Phe-OCH and $\mathrm{D}-\mathrm{Phe}-\mathrm{OC}_{2} \mathrm{H}_{5}$ gave similar degrees of purification, but had different capacities. It has been reported that a larger hydrophobic ester group results in a significantly tighter binding for chymotrypsin ${ }^{15}$ and thus it seemed that slightly larger group of the ethyl ester compared to the methyl ester might contribute to a stronger affinity for papain. The bound proteins of those affinity columns were checked by disc gel electrophoresis (Fig. 4). It was shown that the protein retarded by the Sepharose- $\varepsilon$-AcpL-Leu-D-Phe column gave a single band while the two others gave two bands, respectively.

The three ligands were examined for the inhibition of papain activity using BAPNA as a substrate (Fig. 5). A $60-\mathrm{m} M$ portion of D-Phe- $\mathrm{OCH}_{3}$ or D-Phe- $\mathrm{OC}_{2} \mathrm{H}_{5}$

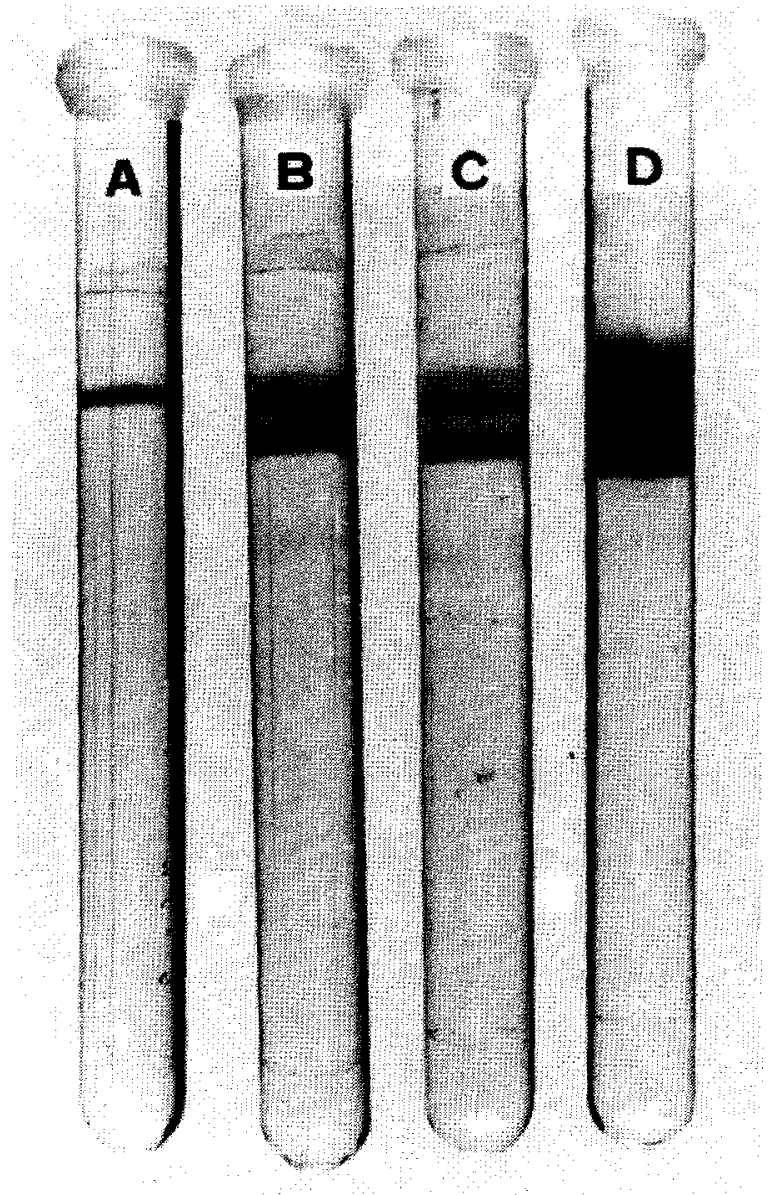

Fig. 4. Disc gel electrophoresis of different preparations of papain. The electrophoresis was carried out in $15 \%$ gel, buffered with glycine-acetate $(\mathrm{pH} 4.0)$ and run at $3 \mathrm{~mA}$ per tube for $1 \mathrm{~h}$. The enzyme preparations were (A) from the sepharose- $\varepsilon$-Acp-L-Leu-D-Phe-OH column $(50 \mu \mathrm{g})$, (B) from the sepharose- $\varepsilon$-Acp-DPhe-OCII 3 column (100 $\mu \mathrm{g})$, (C) from the sepharose-e-Acp-D-Phe-OC ${ }_{2} \mathrm{H}_{5}(100 \mu \mathrm{g})$ and (D) crude papain from Tree Co. $(350 \mu \mathrm{g})$. 


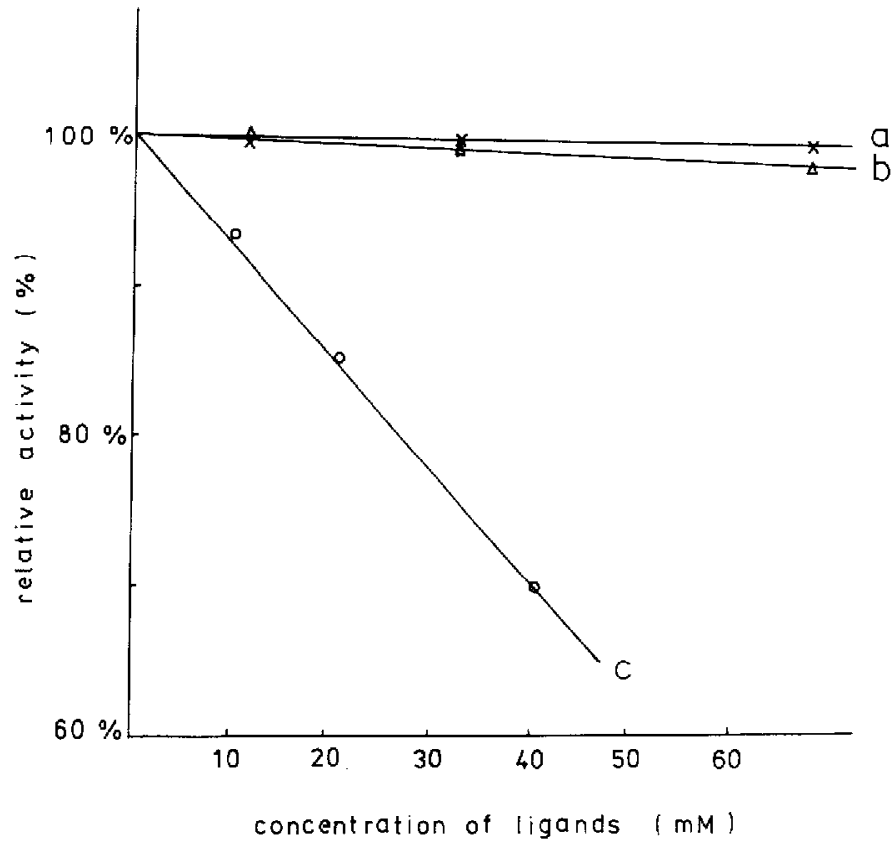

Fig. 5. Incubation of different amounts of ligands with $0.2 \mathrm{mM}$ BAPNA of assay solution containing papain $(27 \mu \mathrm{g})$ purified from the sepharose- 8 -Acp-L-Leu-D-Phe-OH column. The incubation time was prolonged to $1 \mathrm{~h}$. (a) D-Phe- $\mathrm{C}_{2} \mathrm{H}_{5}(\times)$. (b) D-Phe-OCH $(\triangle)$. (c) L-Leu-D-Phe-OH (O).

dissolved in the assay solution had little influence on the papain activity, but $40 \mathrm{mM}$ of L-Leu-D-Phe gave $30 \%$ inhibition. Although the D-Phe-OCH $\mathrm{H}_{3}$ and $\mathrm{D}-\mathrm{Phe}-\mathrm{OC}_{2} \mathrm{H}_{5}$ seem not to be inhibitors for papain, they still could retard it. It implied that the catalysis and the binding occurred at two different sites.

Papain is always reported to be contaminated by the presence of chymopapains. Covalent chromatography by thiol disulphide interchange could distinguish native papain from denaturated papain, but not from chymopapain ${ }^{16}$, since these both possess the same active thiol groups. The sepharose- $\varepsilon$-Acp-L-Leu-D-Phe-OH affinity column described above gave a better purification of papain than those previously reported.

\section{REFERENCES}

1 P. Cuatrecasas, M. Wilchek and C. B. Anfinsen, Proc. Nat. Acad. Sci. U.S., 61 (1968) 636.

2 P. Cuatrecasas and C. B. Antinsen, Ann. Rev. Biochem., 40 (1971) 259.

3 M. Wilcheck and W. B. Jakoby, Methods Enzymol., 34 (1974) 3.

4 C. H. Wong, S. T. Chen and K. T. Wang, J. Chinese Chem. Soc., 24 (1977) 129.

5 C. H. Wong, M. F. Ho and K. T. Wang, J. Org. Chem., 43 (1978) 3604.

6 D. Bobb, Prep. Biochem., 2 (1972) 347.

7 M. Sokolovsky, Methods Enzymol, 34 (1974) 411.

8 J. Turková, K. Bláha and K. Adamová, J. Chromatogr., 236 (1982) 375.

9 J. R. Kimmel and E. L. Smith, J. Biol. Chem., 207 (1954) 515.

10 S. Blumbery, I. Schechter and A. Berger, Eur. J. Biochem., 15 (1970) 97.

11 J. P. Greenstein and M. Winitz, Chemistry of the Amino Acids, Vol. 2, Wiley, New York, 1961, p. 763.

12 A. N. Glazer and E. L. Smith, I. Riol Chem, 736 (1961) 2948.

13 R. Arnon. Methods Enzymol., 19 (1970) 226.

14 B. J. Davis, Ann. N. Y. Acad. Sci., 121 (1964) 404.

15 J. B. Jones and J. F. Beck, in J. B. Jones, C. J. Sih and D. Perlman (Editors). Techniques of Chemistry, Wiley, New York, London, Sydney, Toronto, 1976, vol. 10, p. 107.

16 K. Brocklehurst, J. Carlsson, M. P. J. Kierstan and E. M. Crook, Methods Enzymol., 34 (1974) 531. 